\title{
Nottingham to Ningbo: students as change agents across the globe
}

\author{
Matthew Watts, Carina Neil, Sarah Speight \\ University of Nottingham
}

\section{Introduction}

The University of Nottingham is a global university with campuses in the UK, Malaysia (Kuala Lumpur) and China (Ningbo). There are over 44,000 students in total, with 5,000 in Malaysia and 6,000 in China. Exchange programmes are well-established and the student body is culturally and geographically diverse.

In 2013, the University invested in a four-year 'Transforming Teaching Programme' (TTP), to stimulate educational development across the institution. The TTP supports the University in achieving its Global Strategy 2020 goals of 'put[ting] students at the heart of the University' and 'changing the way we work with our students' (Nottingham 2015: 7). Recognising the sectoral trend of engaging students more purposefully in their education, Nottingham's overarching aim was to develop a model of student engagement that would be distinctive to its own culture and sustainable over time and across all campuses. 'Students as Change Agents' (SACA) was central to this model.

Inspired by the pioneering work of Dunne and Zandstra (2011) in establishing Students as Change Agents at the University of Exeter, the development team investigated a variety of institutional approaches. They evaluated the merits of Birmingham City University's Student Academic Partners, Oxford Brookes University's ePioneers and individual examples of student partnerships (Healey, 2017).

Workshops involving colleagues from the Students' Union, academia and professional services explored what models might fit the Nottingham context: how should we recognise students' contributions? To pay or not to pay? Who should initiate project ideas - staff, students or both? With limited resources, how could we introduce a scheme that would provide consistent experiences and efficient support across all three campuses? The conclusion was that the most effective way to embed student-staff partnership working into university culture by 2020 would be to design a flexible scheme that could support students and staff in transitioning to new ways of working. The scheme would need to:

- support a variety of project themes and contexts, whether creating learning resources, setting up peer mentoring, or working on curriculum developments;

- be easily administered across all campuses;

- reward students and provide them with training.

\section{Launching Students as Change Agents}

Like many UK universities, Nottingham has a student recognition award: the Nottingham Advantage Award (Speight, 2014). This enables students to earn credit for extra- and cocurricular activities and to evidence employability skills. Using the Award as a vehicle to launch SACA provided clear benefits, because it was already well-established, was highly regarded and had support structures in the UK, China and Malaysia. It also justified the decision not to pay Change Agent students for their work; rather than money, students would 


\section{Case Studies}

be recognised for their learning via additional credits that would appear on their degree transcripts.

An Advantage Award SACA module was created to support the overall programme.

Students opting to take the module complete additional assessment tasks, such as a skills audit and a reflective piece. By the end of the $2015 / 16$ academic year, $66 \%$ of UK Change Agents had chosen to do this. Currently, in 2016/17, 86\% of UK students are registered on the SACA module, indicating that linking the scheme to the Advantage Award was a sensible decision.

SACA launched in 2014/15 with four projects, three in the UK and one in China. There was no dedicated SACA support in China at this stage and so the UK team provided advice and guidance, training and assessment. The Malaysia campus chose to observe this initial year and to launch in 2015/16 (details below).

\section{The scheme}

A key characteristic of the scheme is that both staff and students can propose a project. All students are mentored by a staff partner. Most often, students find their staff partner through their own networks: for example, by asking their personal tutor to support them. If students need help in finding a staff partner, the central SACA team will assist by contacting School Directors of Teaching. The nature of the mentoring is flexible, varying according to the needs of students and projects. At one end of the spectrum, the staff partner may work closely with students, contributing pro-actively to project planning and execution, and enabling project outcomes to be applied. At the other end, the staff partner may do little more than keep open her/his offer of support and encourage students to keep to their deadlines.

In respecting this spectrum, the SACA scheme puts student needs and preferences first and recognises that students have agency over their ways of working as well as over the projects they wish to work on. Following approval from the SACA team and academic school leaders (typically the School Director of Teaching or a designated SACA lead), project teams are provided with relevant training. All students complete project management training online and can then choose from a suite of additional online sessions (for example in time management and team building) as most relevant for their project and their personal development needs.

Students then complete project planning and move into the implementation stage. The SACA team monitors progress and steps in to nudge both students and staff partners if momentum is lost.

\section{Review and running the programme}

In the summer of 2015, the pilot year was evaluated. To maintain student leadership of SACA's development, a group of students from across the faculties was employed for this. They conducted surveys and interviews with staff and students who had taken part in projects, analysed data, reviewed all projects and offered recommendations. The reviewers found that the original approach to training and to project start and finish dates, which envisaged the cohort of Change Agents going through the year together, was not feasible. It was essential to keep the scheme as flexible as possible. Subsequently, the same students redeveloped the programme's Moodle page and online training resources. 


\section{Case Studies}

A similar review was conducted in 2016, again by students. The recommendations fell into three categories: project team support, improved online training resources and better promotion. The reviewers advised both the addition of training for reflective writing and a redesign of the scheme's website. Significantly, they also noted the importance of clearlydefined roles within project teams and recommended that supporting students to establish these early on would increase project completion rates and lead to better outcomes. Following endorsement of the review report by the core SACA team, the reviewers were employed to help with the implementation of their recommendations.

In 2016/17, three students have worked throughout the academic year as 'Student Engagement Assistants'. Their role is to develop training, scope new projects with students and staff, carry out induction sessions and provide peer support to students during their project work and administrative support to the overall programme. A review of 2016/17 is also planned, this time with a focus on the impact of the completed projects upon the wider university community and the impact of participation in SACA upon the Change Agents themselves.

Nottingham's SACA scheme embeds partnership working in all areas of its operation. Students are genuinely at its heart, driving its operation and evolution, as well as being partners in individual projects. SACA is run by students for students, in partnership with staff.

\section{Challenges and limitations}

As described above, an original intention was that project teams would progress through the programme together. In the pilot year, project management training was delivered by the university's Professional Development department. However, it soon became apparent that running scheduled sessions was unworkable, owing to the widely differing timetables and availability of both students and staff. It also became clear that simply making available UK session recordings to students in China and Malaysia was insufficient either to engage or support them.

For the second year, following the recommendations of the review report, interactive online training resources were developed. These were designed to nurture key employability skills such as project management, teamwork and communication, and research design. They were built using Xerte Online Toolkits, an open-source format developed by the university's Learning Technology department. Using Xerte Toolkits meant that the resources could include interactive activities (e.g. 'drag and drop') with automated feedback and a variety of formats - text, image and video ${ }^{1}$. Training for SACA was now available seamlessly and consistently across all three campuses, wherever and whenever wanted (and on multiple devices) as long as there was an internet connection. This marked a major improvement on the pilot year, during which only some UK students attended face-to-face training. The move online made the SACA offer accessible and equitable across our global student community a principle that is important at Nottingham.

In addition to the online training, each project team has a personalised induction session with a member of the support team. This enables detailed discussion of how the programme works and of the additional requirements for those doing the Advantage Award. It includes

\footnotetext{
${ }^{1}$ An example training session can be seen at http://www.nottingham.ac.uk/toolkits/play 13074
} 


\section{Case Studies}

basic project management training to help the students with initiating their project. This learning is applied during the same session as the students and their staff partners share and form their ideas. Induction sessions are run on a project-by-project basis and throughout the academic year, meaning that students are no longer tied into set start and finish dates.

\section{Growth and development}

Since SACA's launch, there has been a year-on-year increase in the total number of projects, student-initiated projects and the number of Change Agents (Table 1). The large increase in 2016/17 indicates how awareness of SACA is spreading not only by word of mouth, but also by targeted promotion to students at the start of the academic year.

\begin{tabular}{|l|c|c|c|}
\hline & $\mathbf{2 0 1 4 / 1 5}$ & $\mathbf{2 0 1 5 / 1 6}$ & $\mathbf{2 0 1 6 / 1 7}$ \\
\hline UK & 4 & 7 & 16 \\
\hline China & 1 & 3 & 3 \\
\hline Malaysia & - & 3 & 5 \\
\hline
\end{tabular}

Table 1. No. of projects across campuses and years

\section{Launching internationally - China and Malaysia}

SACA's implementation and growth in the UK, China and Malaysia have not been simultaneous. Start dates and timescales have been at the discretion of the TTP senior sponsors at each campus, not out of any managerial wish to control the scheme, but because of the resource implications of running it. There has been no central mandate enforcing one model and pace on all campuses. An academic lead appointed in Malaysia in 2015/16 became convenor for the Advantage Award module there, adapting it to fit local needs. Thus, in Malaysia, unlike in the UK, where students have the option to participate in SACA without working for Advantage Award credits, it was decided that SACA should sit entirely within the Nottingham Advantage Award. This was a strategic decision, to avoid dilution of the Advantage Award, which was then in its first significant expansion phase. SACA is now established in Malaysia and there have been three successful projects.

There was no academic lead in China for 2015/16 and the three projects that year accessed UK support for training and assessment. In 2016/17, both administrative support and academic leadership were put in place to plan a full launch. Whilst in the UK students were employed to review SACA and subsequently to develop it, the China campus has adopted an even more integrated model by commissioning a SACA project to design the processes and resources best suited for SACA in the context of Nottingham's Ningbo campus.

The eight projects in Malaysia and the six projects in China that have been commissioned to date mirror the topics that attract the most interest in the UK. Peer support initiatives are to the fore, followed by projects to evaluate feedback and review course materials. While the projects are broadly similar, the ways in which the projects are carried out may differ. Cultural norms as well as disciplinary traditions can impact upon team working and upon the relationships between students and staff. SACA staff in the UK, China and Malaysia work collaboratively together to approve projects and share information and outcomes, while recognising that local autonomy in the shaping of the programme is essential to ensure that student needs and interests, rather than any desire for standardisation, dictate the evolution 


\section{Case Studies}

of SACA. To succeed, SACA must be adaptable to its context and the staff and students on the ground are best placed to judge this.

\section{Projects, reach and impact ${ }^{2}$}

SACA reinforces the engagement and active commitment of our Change Agent students to their studies and to their peers. It enables them to make a difference in their academic school and to leave a positive legacy of their time at Nottingham. It is notable that, whilst projects have covered many areas (e.g. assessment and feedback, work placements, exchange programmes, reading strategies), the greatest impact has been made by the peer support schemes. Change Agents have shown a deep commitment to the support of fellow students and have recognised the benefits of learning with, and from, each other. The following are two examples of projects that have delivered significant benefits to whole student cohorts.

\section{Maths - Peer Assisted Study Support (PASS)}

In the School of Mathematical Sciences, Change Agent students developed a PASS scheme, with second- and third-year students providing peer support to first-year students to help their transition to university-level maths. In 2014/15, these Change Agents devised the content of the scheme, organised its logistics and recruited PASS Leaders from their own peer group. In 2015/16, they implemented the scheme, with timetabled fortnightly PASS sessions, and established processes to make the scheme sustainable, such as recruitment guidance for future PASS Leaders. In 2016/17, a new group of students, who were PASS Leaders in 2015/16, are working to expand the scheme and create sessions for those who wish to challenge themselves with more difficult mathematical concepts.

\section{Pharmacy - mock Objective Structured Clinical Examinations (OSCEs)}

In the school of Pharmacy, Change Agent students established mock OSCEs. They recruited and trained their peers in senior years to act as demonstrators (patients and markers). Having developed scenarios and organised, advertised and run sessions, they then evaluated feedback from participants to inform further development. In 2016/17, SACA students are expanding the scheme and ensuring its sustainability by producing videos of example scenarios and good responses.

\section{Reach}

Figure 1 is available at: https://flic.kr/p/FQgyuZ

Figure 1. The reach of Students as Change Agents at the University of Nottingham (UK Campus)

Data from the UK campuses shows that, since inception in 2014/15, SACA projects have impacted upon the experiences and learning of over 1200 students (See Figure 1.). This number includes those students who have been Change Agents, those benefiting from the work done by Change Agents and those who have been employed as Student Engagement

\footnotetext{
${ }^{2}$ Further details of Students as Change Agents projects can be found here: http://www.nottingham.ac.uk/toolkits/play 15190
} 


\section{Case Studies}

Assistants. It highlights the spread of the programme across Nottingham's faculties and professional services and indicates where further effort is required to increase uptake.

The annual reviews include surveys of both students and staff. This has provided qualitative evidence of the impact of SACA upon participants and the sense of community that the projects help foster. For example:

"I really think that this Change Agents project has been one of the most rewarding things I've done at Nottingham and I am incredibly proud of everything we have achieved." (Student, 15/16)

"It's been one of the most fun things l've done in my 20 years at University." (Staff Partner, 14/15)

"This is a tremendous opportunity for staff to learn from students, to question their practice and particularly to address prejudice about what students think and want [...] The value of SACA for transforming teaching and learning and enhancing its quality through dialogue and mutual understanding is exceptional; it also creates a genuine space for student engagement." (Staff Partner, 15/16)

In $2015 / 16,95 \%$ of twenty student respondents agreed or strongly agreed that undertaking their project was an enjoyable experience, $75 \%$ agreed or strongly agreed that their projects fulfilled their expectations and $95 \%$ agreed or strongly agreed that their work had made or would make a positive impact on their school.

In spring 2016, the UK's Quality Assurance Agency (QAA) reviewed the University's provision. In their report, they commended the SACA programme as 'emblematic' of 'the University's embedded engagement with students in the enhancement of their learning opportunities' (QAA: 42/43). Having the programme recognised externally further validates the quality of the students' work. The central SACA team proactively flag to project teams opportunities for dissemination and celebration; one team has presented at the UK's 'Researching, Advancing and Inspiring Student Engagement 2016' conference and Jisc Change Agents' Network Conference, whilst the Maths PASS team has published about its work (Cox, Cook and Nield 2016). A SACA project in Health Sciences ('Peer-led clinical skills') won the prestigious Student Nursing Times 2017 'Teaching Innovation of the Year' award.

\section{Conclusion}

The SACA programme at Nottingham has enjoyed a positive start, with several successful projects. It is a vehicle to support a growing number of productive student-staff partnerships. One of the main challenges going forward is to ensure that the programme remains studentled, with a focus upon quality and impact rather than quantity. From SACA projects completed to date, it is clear that small numbers of dedicated students working in partnership with staff can produce high-quality work that makes a real difference to the broader student experience. Keeping the SACA experience consistently high in quality across all campuses is also a challenge. But, the effort of establishing and adapting the scheme for its UK, China and Malaysia contexts has resulted in the creation of a strongly collaborative and collegiate cross-campus team, sharing common values but also respecting local differences.

Nottingham is committed to the continuing support of SACA, student engagement and partnership. SACA is now on the cusp of moving from 'new initiative' to 'business as usual'. 


\section{Case Studies}

It has been commended by the QAA and included as an example of good practice in the University's first written submission to the UK's 'Teaching Excellence Framework' (TEF). Going forward, as Nottingham and those other UK institutions with SACA-type schemes await the outcomes of the TEF, it will be interesting to see how highly the UK government values such higher education programmes as these.

\section{Reference list}

Cox, S., Cook, L. and Nield, S. (2016) 'Peer Assisted Study Support (PASS) and Students as Change Agents (SACA) in Mathematics at the University of Nottingham.' MSOR Connections, 14(3), 32-38.

Dunne, E. and Zandstra, R. (2011) Students as change agents - new ways of engaging with learning and teaching in higher education. Bristol: A joint University of Exeter/ESCalate/HEA publication. Available at: http://escalate.ac.uk/8064 (Accessed: 31 January 2017).

Healey, M. (2017) Students as partners and change agents in learning and teaching in higher education. Available at: www.mickhealey.co.uk/resources (Accessed: 2 February 2017).

Speight, S.J. (2014) The Nottingham Advantage Award.' In: Jackson, N. and Willis, J. (eds.) Lifewide Learning and Education in Universities and Colleges. Lifewide Education Community (Chapter B1). Available at: http://www.learninglives.co.uk/e-book.html (Accessed: 2 February 2017).

Learning Technology, University of Nottingham. Available at: https://www.nottingham.ac.uk/library/help/learningtech.aspx (Accessed: 5 February 2017).

Quality Assurance Agency (QAA) (2016) Higher Education Review of the University of Nottingham. Available at: http://www.qaa.ac.uk/reviews-andreports/provider?UKPRN=10007154\#.WHy-7tKLSCj (Accessed: 5 February 2017).

University of Nottingham (2015) Global Strategy 2020. Nottingham: University of Nottingham. Available at: https://www.nottingham.ac.uk/about/strategy/index.aspx (Accessed: 5 February 2017).

Xerte Online Toolkits. Available at: https://www.nottingham.ac.uk/xerte/index.aspx (Accessed: 5 February 2017). 